\title{
Chronic thromboembolic pulmonary hypertension and vascular transformation of the lymph node sinuses
}

\author{
M. Meysman*, M. Diltoer**, H.D. Raeve+, I. Monsieur*, L. Huyghens**
}

\begin{abstract}
Chronic thromboembolic pulmonary hypertension and vascular transformation of the lymph node sinuses. M. Meysman, M. Diltoer, H.D. Raeve, I. Monsieur, L. Huyghens. (c)ERS Journals Ltd 1997.

ABSTRACT: Chronic thromboembolic pulmonary hypertension (CTEPH) is a disease often not recognized until it is far advanced. Medical management does not reverse the effects of the disease, nor does it prevent its progression. Pulmonary thromboendarterectomy is the preferred treatment.

We present the case of a patient in whom CTEPH was mistaken for an interstitial lung disease with mediastinal lymph node enlargement. The mediastinal lymph node enlargement was due to vascular transformation of the lymph node sinuses (VTS). This is an unusual case of chronic thromboembolic pulmonary hypertension with vascular transformation of the lymph node sinuses. Eur Respir J 1997; 10: 1191-1193.
\end{abstract}

*Respiratory Division, Dept of Internal Medicine, **Dept of Critical Care Medicine and +Dept of Pathology, Academic Hospital, University of Brussels (AZ-VUB), Brussels, Belgium.

Correspondence: M. Meysman, Respiratory Division, Academic Hospital, University of Brussels (AZ-VUB), Laarbeeklaan 101, 1090 Brussels, Belgium

Keywords: Chronic thromboembolic pulmonary hypertension

vascular transformation of the lymph node sinuses

Received: July 161996

Accepted after revision November 251996
Chronic thromboembolic pulmonary hypertension (CTEPH) is a rare but potentially treatable cause of pulmonary hypertension. Unfortunately, there is often a delay in the diagnosis due to the fact that signs and symptoms are nonspecific in the majority of these patients. For this reason, CTEPH is frequently mistaken for other entities, such as chronic obstructive pulmonary disease, coronary artery disease, interstitial lung disease, congestive heart failure, or psychosomatic dyspnoea [1].

We present the case of a patient in whom enlarged mediastinal lymph nodes and a mosaic pattern of lung attenuation on chest computed tomography (CT) scan were mistaken for interstitial lung disease. At autopsy, CTEPH and vascular transformation of the lymph node sinuses (VTS) were found.

\section{Case report}

A 32 year old male was transferred to our institution because of respiratory distress and haemoptysis after transbronchial biopsy. Since the age of $10 \mathrm{yrs}$, the patient had been treated with inhaled $\beta_{2}$-mimetics on demand, for allergic asthma. He had a smoking history of 15 pack-years but had ceased smoking 3 yrs before admission. Varicectomy of the lower limbs had been performed 2 yrs earlier.

The patient was examined at another hospital a few months before admission because of worsening exertional dyspnoea and wheezing. Inhaled corticosteroids, budesonide $400 \mathrm{mg} \cdot \mathrm{day}^{-1}$, were added to his treatment, without any improvement in his symptoms. Spirometry performed at that time showed moderate obstructive pulmonary disease, with significant bronchial hypersensitivity at histamine provocation testing (provocative dose causing a $20 \%$ fall in forced expiratory volume in one second (PD20) $\left.0.8 \mathrm{mg} \cdot \mathrm{mL}^{-1}\right)$. A chest radiograph was reported to show cardiac enlargement and pulmonary hyperinflation. An electrocardiogram revealed sinus rhythm with inverted $\mathrm{T}$-waves in the precordial leads, and an echocardiogram demonstrated considerable enlargement of the right atrium and ventricle. Mean pulmonary artery pressure by Doppler evaluation of the tricuspid regurgitant envelope was estimated at $42 \mathrm{mmHg}$. A CT scan of the chest (fig. 1a and b) revealed mediastinal lymph node enlargement and a mosaic pattern of lung attenuation, suggesting interstitial lung disease.

Bronchoscopy and transbronchial biopsy were performed but haemoptysis and respiratory distress developed soon afterwards. The patient was intubated, mechanically-ventilated and transferred to our hospital.

On admission, physical examination revealed a blood pressure of $80 / 64 \mathrm{mmHg}$, with a regular tachycardia of 150 beats $\mathrm{min}^{-1}$. A grade 2 holosystolic murmur was heard at the cardiac apex. Scattered ronchi and a pleural rub were present bilaterally. The liver edge descended $2 \mathrm{~cm}$ below the right costal margin. No lymphadenopathy was found. There was no splenomegaly. Rectal examination was negative. There was no peripheral oedema.

Laboratory values showed a haematocrit of $43 \%$, a white cell count of $12.5 \times 10^{9}$ cells $\cdot \mathrm{L}^{-1}$ with a normal differential count. The platelet count was $175 \times 10^{9}$ platelets $\cdot \mathrm{L}^{-1}$. The prothrombin time was $18.5 \mathrm{~s}$, with a partial thromboplastin time of $40 \mathrm{~s}$. Blood urea nitrogen and serum creatinine were normal. Lactic dehydrogenase was elevated at $826 \mathrm{U} \cdot \mathrm{L}^{-1}$ (normal level 241-549 $\left.\mathrm{Y} \cdot \mathrm{L}^{-1}\right)$. Serum aspartate aminotransferase and creatinine kinase were normal. Marked metabolic acidosis was present: $\mathrm{pH}$ 7.22; arterial carbon dioxide tension $\left(\mathrm{Pa}_{\mathrm{a}} \mathrm{CO}_{2}\right) 6.4 \mathrm{kPa}(48 \mathrm{mmHg})$; arterial oxygen tension 
a)

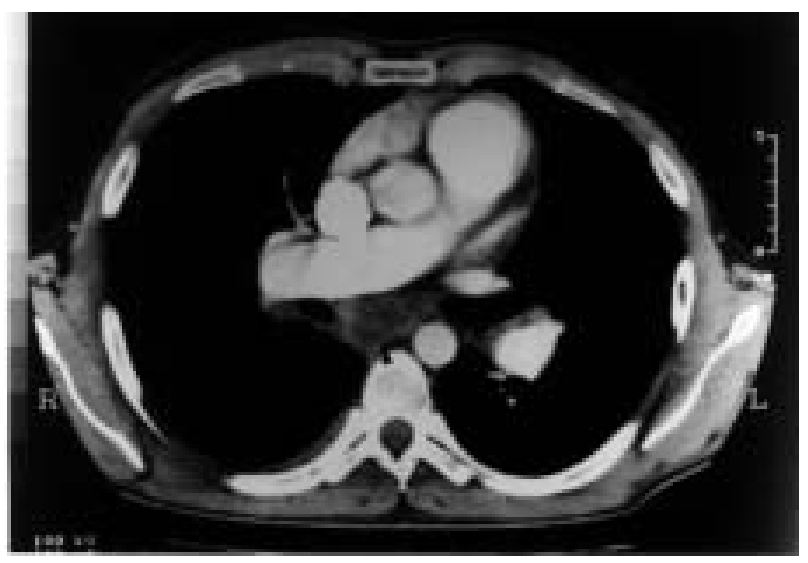

b)

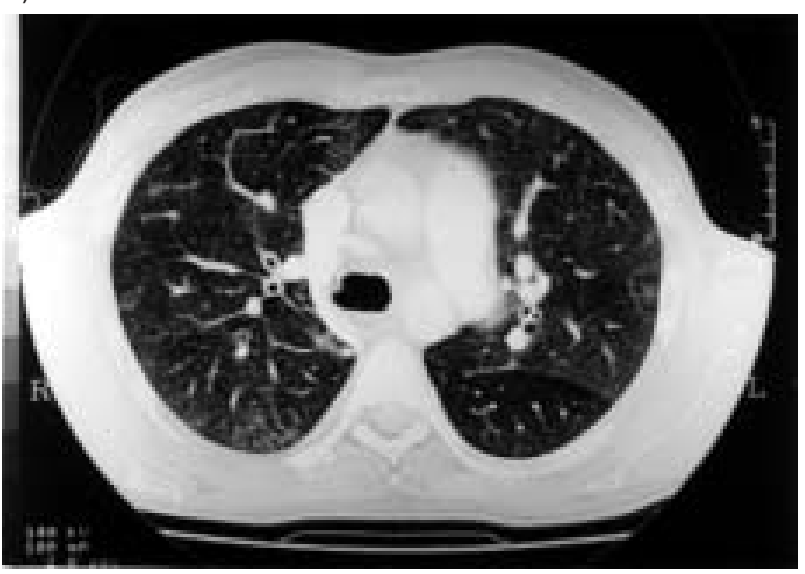

Fig. 1. - a) Computed tomography (CT) scan of the chest, slice thickness $5 \mathrm{~mm}$ (at the level of the right main pulmonary artery): revealing mediastinal lymph node enlargement (arrow). b) CT scan of the chest, slice thickness $5 \mathrm{~mm}$ (at the level of the azygos vein): showing a mosaic pattern of lung attenuation.

$\left(\mathrm{Pa}, \mathrm{O}_{2}\right) 9.5 \mathrm{kPa}(71 \mathrm{mmHg})$; arterial oxygen saturation $\left(\mathrm{Sa}_{\mathrm{a}} \mathrm{O}_{2}\right) 0.89$ at an inspired oxygen concentration of $100 \%$.

At that time, the electrocardiogram showed sinus tachycardia, 150 beats $\cdot \mathrm{min}^{-1}$, with complete right bundle branch block. At bronchoscopy, residual blood was seen in the right lower bronchus, but there was no active bleeding. Bedside pulmonary artery catheterization revealed a pulmonary wedge pressure of $17 \mathrm{mmHg}$, and pulmonary arterial pressure was $91 / 62 \mathrm{mmHg}$ with a mean pressure of $74 \mathrm{mmHg}$. Pulmonary vascular resistance was 800 dynes $\cdot \mathrm{s} \cdot \mathrm{cm}^{-5}$, and the systemic vascular resistance 497 dynes $\cdot \mathrm{s} \cdot \mathrm{cm}^{-5}$. Blood pressure at this time was $80 / 46$ $\mathrm{mmHg}$, mean $58 \mathrm{mmHg}$. Cardiac index was $3.2 \mathrm{~L} \cdot \mathrm{min}^{-1} \cdot \mathrm{m}^{2}$. No intracardiac shunt was present. These haemodynamic data were obtained while the patient received intravenous dobutamine $40 \mathrm{~g} \cdot \mathrm{kg}^{-1} \cdot \mathrm{min}$, dopamine $40 \mathrm{~g} \cdot \mathrm{kg}^{-1} \cdot \mathrm{min}$, norepinephrine $1 \mu \mathrm{g} \cdot \mathrm{kg}^{-1} \cdot \mathrm{min}$, and was mechanicallyventilated with an additional $12 \mathrm{cmH}_{2} \mathrm{O}$ of positive endexpiratory pressure (PEEP).

Chest radiography revealed bilateral diffuse alveolar infiltrates with cardiac enlargement. Transoesophageal echocardiography confirmed the right atrial and ventricular enlargement. Paradoxical motion of the interventricular septum and tricuspid regurgitation were also detected. Atrial septal defect could be ruled out.

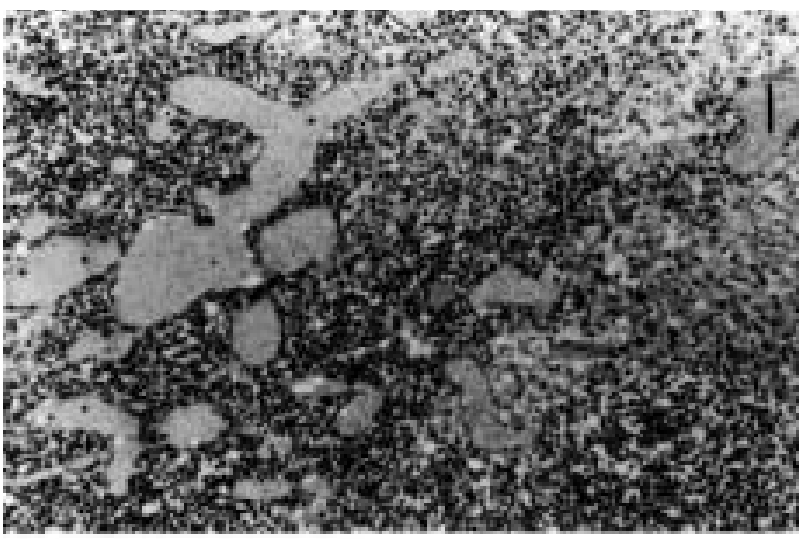

Fig. 2. - Postmortem lymph node biopsy ( $5 \mu \mathrm{m}$ slice, high power view): showing rounded vascular spaces engorged with blood and lined by endothelial cells. (Haematoxylin and eosin stain; internal scale bar $=50 \mu \mathrm{m})$.

The patient's clinical condition deteriorated and, despite cardiopulmonary resuscitation, he died $12 \mathrm{~h}$ after arrival in the intensive care department. At autopsy, the principal findings were in the lungs and the heart. Severe cor pulmonale with dilatation and hypertrophy of the right heart was present. The heart weighed $850 \mathrm{~g}$. There was severe atherosclerosis of the main pulmonary arteries. Several small elastic pulmonary arteries were occluded by thromboemboli. Microscopic examination of these arteries revealed fibrous organization, with partial recanalization. More distally, concentric intimal hyperplasia and slight medial thickening were observed. No acute pulmonary infarcts were seen. The pulmonary veins appeared normal. No plexogenic arteriopathy existed. Vascular transformation of the mediastinal lymph node sinuses was present (fig. 2). There was venous insufficiency of the leg veins, but no thrombi were found in these veins. Examination of the liver and spleen showed chronic congestion due to cardiac failure.

\section{Discussion}

Pulmonary embolism is largely undiagnosed because, in most instances, clinical suspicion is not raised and, thus, patients with pulmonary embolism often go undetected [2]. Fortunately, most survivors recover without any clinically relevant sequelae after an embolic event [3]. In contrast with former beliefs, however, most pulmonary thromboemboli are not cleared from the microcirculation. Autopsy studies show the residue of chronic, partially recanalized thrombi in virtually all individuals who have had prior pulmonary emboli [4]. However, it remains an exception that pulmonary hypertension due to chronic large vessel pulmonary thrombi or extensive microvascular obstruction (CTEPH) ensues [5]. CTEPH is estimated to develop in only $0.1-0.5 \%$ of patients suffering an acute embolic event [6].

From a diagnostic point of view, this case presented significant difficulty, not least because of the finding of enlarged mediastinal lymph nodes. On histological examination, all the lymph nodes exhibited vascular transformation of the lymph nodes sinuses (VTS). This is a histopathological entity first described by HAFERKAMP et al. [7] in 1971, mimicking lymphoma and Kaposi's 
sarcoma. The spectrum of histological features observed in VTS is probably a continuum between nodal angiomatosis, a nodular lesion of vascular channels, on the one hand and nodular spindle cell vascular transformation of lymph nodes, a nodular proliferation of vesselrelated spindle cells, on the other [8]. Four major patterns of vascular proliferation are observed: cleftlike spaces of sinuous vascular slits; rounded vascular spaces; solid foci of spindle or plump cells; and the uncommon plexiform pattern. This vascular transformation is often associated with variable degrees of sclerosis. It appears that the predominant pattern may be determined in part by the location of the lymph node. The fibrous capsule of the lymph node is never involved in the vasoproliferative process $[8,9]$.

Obstruction of the efferent lymph node vessels or lymph node venous obstruction is believed to play a major pathogenetic role in the development of VTS [10]. Thrombosis of perinodal blood vessels could only be identified in 5 out of 76 cases reported by CHAN et al. [9], although in 54 of these 76 patients distal lymphatic or venous obstruction was present and probably favoured the development of VTS. In our patient, marked stasis was present in the liver and spleen, suggesting a serious outflow problem in the right heart due to CTEPH.

Alternative mechanisms, such as angiogenetic factors, may be operative in some instances [9]. An emerging role of release of platelet selective mediators, such as serotonin, thromboxane- $\mathrm{A}_{2}$ and growth factors, in the development of CTEPH is under investigation [11]. It is not impossible that these factors may also induce changes in the adjacent lymph nodes.

In conclusion, we present the unusual association of mediastinal lymph node enlargement due to vascular transformation of the lymph node sinuses in a patient with chronic thromboembolic pulmonary hypertension.

\section{References}

1. Shure D. Chronic thromboembolic pulmonary hypertension: diagnosis and treatment. Semin Respir Crit Care Med 1996;17(1): 7-15.

2. Modan B, Sharon E, Jelin N. Factors contributing to the incorrect diagnosis of pulmonary embolic disease. Chest 1972; 62: 388-393.

3. Benotti JR, Dalen JE. The natural history of pulmonary embolism. Clin Chest Med 1984; 5: 403-410.

4. Karwinski B, Svendsen E. Comparison of clinical and postmortem diagnosis of pulmonary embolism. J Clin Pathol 1989; 42(2):135-139.

5. Auger WR, Fedullo PF, Channick RN, et al. Pulmonary embolism: when the acute becomes chronic. Emerg Med 1994; 26(8): 19-42.

6. Fedullo PF, Auger WR, Channick RN, et al. Chronic thromboembolic pulmonary hypertension. Clin Chest Med 1995; 16(2): 353-374.

7. Haferkamp O, Rosenau W, Lennert K, et al. Vascular transformation of lymph node sinuses due to venous obstruction. Arch Pathol 1971; 92(2): 81-83.

8. Cook PD, Czerniak B, Chan JKC, et al. Nodular spindle cell vascular transformation of lymph nodes: a benign process occuring predominantly in retroperitoneal lymph nodes draining carcinomas that can simulate Kaposi's sarcoma or metastatic tumor. Am J Surg Pathol 1995; 19(9): 1010-1020.

9. Chan JKC, Warnke RA, Dorfman R. Vascular transformation of sinuses in lymph nodes: a study of its morphological spectrum and distinction from Kaposi's sarcoma. Am J Surg Pathol 1991; 15: 732-743.

10. Ostrowski ML, Siddiqui T, Barnes RE. Vascular transformation of lymph node sinuses: a process displaying a spectrum of histologic features. Arch Pathol Lab Med 1990; 114(7): 656-660.

11. Chaouat J, Weitzenblum E, Higenbottam T. The role of thrombosis in severe pulmonary hypertension. Eur Respir $J$ 1996; 9: 356-363. 